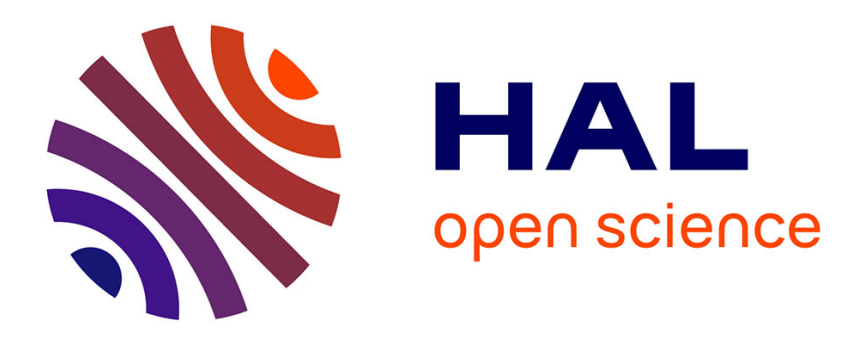

\title{
Manufacturing modelling, management and control: IFAC TC 5.2 past, present and future
}

\author{
Alexandre Dolgui, Dmitry Ivanov
}

\section{To cite this version:}

Alexandre Dolgui, Dmitry Ivanov. Manufacturing modelling, management and control: IFAC TC 5.2 past, present and future. Annual Reviews in Control, 2020, 49, pp.258-263. 10.1016/j.arcontrol.2020.04.003 . hal-03170925

\section{HAL Id: hal-03170925 \\ https://hal.science/hal-03170925}

Submitted on 25 May 2021

HAL is a multi-disciplinary open access archive for the deposit and dissemination of scientific research documents, whether they are published or not. The documents may come from teaching and research institutions in France or abroad, or from public or private research centers.
L'archive ouverte pluridisciplinaire HAL, est destinée au dépôt et à la diffusion de documents scientifiques de niveau recherche, publiés ou non, émanant des établissements d'enseignement et de recherche français ou étrangers, des laboratoires publics ou privés. 


\title{
Manufacturing Modelling, Management and Control: \\ IFAC TC 5.2 past, present and future
}

\author{
Alexandre Dolgui ${ }^{1}$, Dmitry Ivanov ${ }^{2 *}$ \\ ${ }^{1}$ IMT Atlantique, LS2N - CNRS, La Chantrerie, 4 rue Alfred Kastler, 44307 Nantes, France \\ E-Mail: alexandre.dolgui@imt-atlantique.fr \\ ${ }^{2}$ Berlin School of Economics and Law \\ Supply Chain and Operations Management, 10825 Berlin, Germany \\ Phone: +49 30 85789155; E-Mail: divanov@ hwr-berlin.de
}

* Corresponding author

\begin{abstract}
:
In this position paper, we summarize history, current activities and future topics of IFAC Technical Committee (TC) 5.2 "Manufacturing Modelling for Management and Control". As a special focus, we discuss the results of the 9th IFAC Conference MIM 2019 that was recently organized by IFAC TC 5.2 in Berlin, Germany and attended by 740 participants. We analyse the current activities of the working groups within TC 5.2 and project some future research directions. Finally, we present an overview of papers from TC 5.2 in this special issue.
\end{abstract}

Keywords: control, management, modelling, manufacturing, logistics, Industry 4.0

\section{History of IFAC MIM (Manufacturing Modelling, Management and Control)}

Control belongs to the fundamental disciplines in manufacturing modelling and management. Control applications to manufacturing systems and supply chains have numerous directions such as planning, scheduling, inventory control, supply chain resilience and risk management, to name a few (Nof 2007, Dolgui and Proth 2010, Ivanov et al. 2018, Dolgui et al 2019). Modern production and logistics systems, supply chains, and Industry 4.0 networks are challenged by increased uncertainty and risks, multiple feedback cycles, and dynamics. In this setting, control theory contains a set of unique features such as feedback control, adaptation, dynamic modelling (Sethi et al. 2002, Wang and Disney 2012, Spiegler 2016, Ivanov et al. 2016) which are of an increased interest for manufacturing research community.

IFAC MIM - Manufacturing Modelling, Management and Control has been founded during the IFAC World Congress in Sydney in 1993. Indeed, the history started in 1989, when Prof. A. Villa organized the IFAC-CIRP-IFIP-IFORS International Workshop on Decisional Structures in Automated Manufacturing, in Genova (Italy), September 18-21, with a successful participation and the relevant support of national enterprises.

In 1993, the IFAC Technical Committee (TC) on MIM "Manufacturing Modelling, Management and Control" (initially named as M3C but then re-named in MIM) was established and started working, with a first Workshop MIM'97 in Vienna, February 3-5, 1997, organized by the Technical University of Vienna (Prof. P. Kopacek), a co-sponsored by several IFAC TCs 
as well as by IFIP and IFORS. The successful MIM development over this period is to thank to the IFAC TC 5.2 founder and the first chair Prof. A. Villa (Chair 1993-1999).

The next IFAC Symposium on MIM has been held in Rio, Greece, July 12-14, 2000. Then MIM symposium was renamed in MIM conference and organized in 2001, in Prague, at the Czech Academy of Sciences. The following one has been held in Athens, 2004 (5th MIM), and then in Budapest, 2007 (6th MIM). The successful MIM development over this period is to thank to the IFAC TC 5.2 chairs Prof. S. Y. Nof (Chair 1999-2002), Prof. L. Monostori (Chair 20022008), and Prof. J. Ceroni Diaz (Chair 2008-2011).

In 2013, under the chairmanship of Prof. A. Dolgui (IFAC TC 5.2 Chair in 2011-2017), the 7th IFAC MIM conference (St. Petersburg, Russia, June 2013, NOC Chair: Prof. N. Bakhtadze, IPC Chair: Prof. A. Dolgui) and 8th MIM conference (June 2016, Troyes, France; General Chair: Prof. F. Yalaoui, Steering Committee Chair: Prof. A. Dolgui, IPC Chair: Prof. R. Grubbström) have been organized at a large scale by IFAC TC 5.2. The $9^{\text {th }}$ IFAC MIM 2019 has been held in Berlin (Germany) in August 2019 (General Chair: Prof. D. Ivanov - TC 5.2 Chair since 2017, IPC Chair: Prof. A. Dolgui). Number of participants at MIM conference has been continuously increased for the last three events (450 at MIM 2013 in St. Petersburg, 540 at MIM 2016 in Troyes, 740 at MIM 2019 in Berlin) (Fig. 1.).

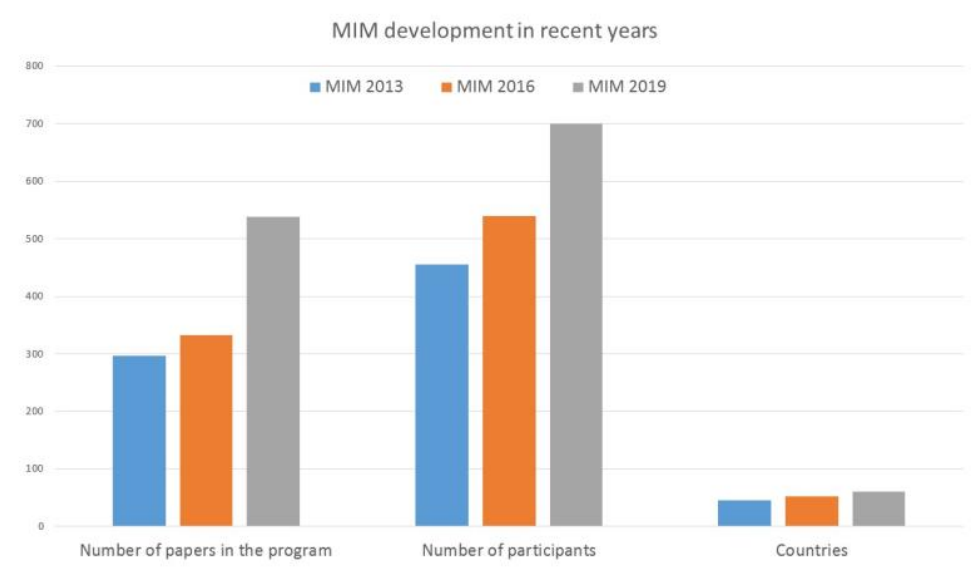

Fig. 1. Number of participants at the last MIM conferences in 2013-2019

\section{Scope of IFAC TC5.2}

The activities of the IFAC TC 5.2 "Manufacturing Modelling for Management and Control" are devoted to promote the development of management decision-support systems in digital, resilient and sustainable manufacturing and supply networks in the era of Industry 4.0 based on combination of Control theory, Industrial Engineering, and Production Management (Fig. 2). 


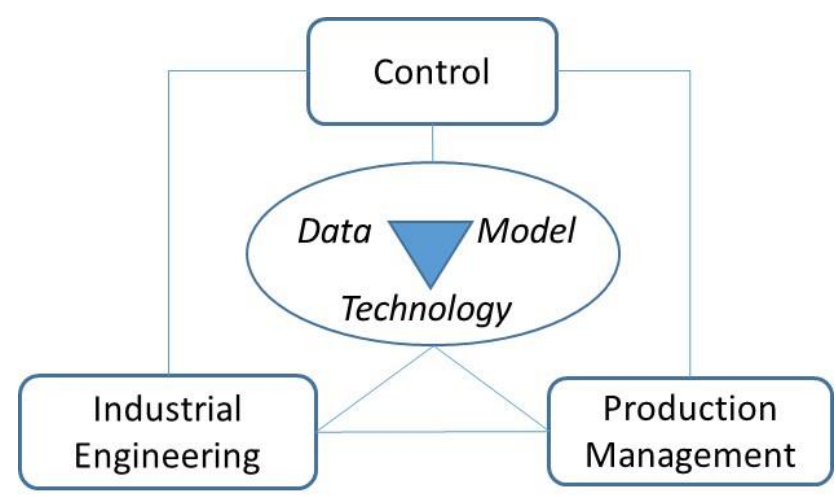

Fig. 2. IFAC TC 5.2 vision of multi-disciplinary research in manufacturing modelling, management and control

Models for manufacturing management and control range from optimization and knowledgebased models to simulation models (discrete-event and continuous), all of them oriented to design of production systems and supply networks, production and supply chain management.

Technical areas of interest in TC 5.2 include the following elements:

(a) Models of manufacturing tasks in production as well as assembly units, with the aim of designing architectures of workstations, cells and production lines, quality assurance and maintenance;

(b) Models of manufacturing processes aiming at the design of procedures for process planning, production planning and control, job and activity scheduling, inventory control and logistics;

(c) Models of supply networks aiming at the design, planning and control of coordinated production-logistics systems;

(d) Models of Industry 4.0, cyber-physical systems, computer-aided, communication-based and Internet-based procedures and processes with the aim of accomplishing the functions listed in (a) - (c).

The IFAC Technical Committee 5.2 on Manufacturing Modelling for Management and Control is composed of 91 members from 22 countries organized in 7 working groups.

The committee is a part of IFAC Coordinating Committee CC 5 "Manufacturing and Logistics" and cooperates with other TCs 5.1, 5.3, and 5.4, as recently documented in Panetto et al. (2019).

\section{IFAC Conference MIM 2019}

$9^{\text {th }}$ IFAC MIM 2019 took place in Berlin, Germany on August 27-30, 2019. The conference covered all topics related to design, modelling and management of modern manufacturing systems and supply networks. It was co-sponsored by IFIP, IFORS, IISE, and INFORMS.

The MIM 2019 mission was to connect Control, Industrial Engineering, OR and Computer Science for better management decision-support systems in digital, resilient and sustainable manufacturing and supply chains in the era of Industry 4.0, to present and discuss emerging topics in modern manufacturing modelling, management, and control. MIM 2019 followed a rich tradition of previous IFAC conferences and symposia in Manufacturing and Logistics.

The national organization committee of MIM 2019 was led by Prof. Dr. Harald Gleissner $f$ and Prof. Dr. Susanne Meyer. More than 850 submissions from 61 countries were received. Finally, after a careful peer-review process with a voluntary involvement of 94 members of International 
Program Committee from 31 countries and more than 700 reviewers, 540 articles have been selected for presentation at the conference. In the outstanding program of MIM 2019 were included: 7 plenary talks, 5 keynote talks, 540 presentations in 18 parallel tracks with 121 invited, special and regular sessions, 4 industrial sessions, and several thematic special sessions (e.g., Meet the Editor session with Editor-in-Chiefs of the leading international journals). Several exhibitors (e.g., The AnyLogic Company, SupplyOn AG, Springer), industrial tours at BMW, Fraunhofer IPK, Rolls Royce, Siemens, and Stadler, and 3 Industrial Workshops shaped the industrial program of the IFAC MIM 2019. An educational seminar and a PhD workshop contributed to the educational aspects in the research domain of MIM 2019.

The outstanding plenary talks have been delivered by:

- Prof. Dr. Richard Hartl "Solution approaches and incentive schemes in collaborative logistics planning";

- Prof. Dr. Lenny Koh "What really matters today and in the future - From physical to digital to autonomous";

- Prof. Dr.-Ing. Holger Kohl "Modular Shopfloor-IT - Intelligent Process Management of Customer-Specific Products";

- Mr. Andreas Oroszi "Digitalization at Festo - Our way in digital transformation";

- Prof. Dr. Boris Sokolov "Planning and scheduling by optimal control: fundamentals and applications to cyber-physical and Industry 4.0 systems";

- Prof. Dr. Srinivas (Sri) Talluri "Models for Evaluating and Monitoring Efficiency of Supply Chain Network Designs";

- Prof. Dr. Christopher Tang "Supply Chain Operations in the Industry4.0 Era".

In addition, exciting Track keynotes have been done by Prof. Dr. Cihan H. Dalgi, Prof. Dr. Dorit S. Hochbaum, Prof. Dr. Erwin Pesch, Prof. Dr. Subhash C. Sarin, and Prof. Dr. Manoj K. Tiwari.

\section{MIM 2019 in Numbers:}

740 participants

94 leading scientists from 30 countries in the International Program Committee

61 countries were represented via the contributors

774 submitted full papers (not abstracts)

$\mathbf{7 8}$ submitted extended abstracts

$\mathbf{7 8 1}$ reviewers participated in the peer review process

2000 reviews received approximately (with a minimum of 2 reviews per paper)

494 full papers and 61 extended abstract accepted after the peer review process

$\mathbf{6 3 . 8 \%}$ acceptance rate for full papers

540 presentations in the technical sessions

478 full papers in the Proceedings

2838 pages in the Proceedings

7 plenary speakers

5 keynote speakers

$\mathbf{3}$ industrial workshops

$\mathbf{2 8}$ prizes for the best papers presented

10 Special Issues in the international journals are associated with the MIM 2019 for post-conference publication. 


\section{Major research challenges and future perspectives}

The major research challenges in manufacturing modelling, management and control and potential future topics are analysed within seven working groups (WG) of IFAC TC 5.2.

WG 1 "Supply Network Engineering"; Chairs: Prof. Dr. Alexandre Dolgui (France), Prof. Dr. Dmitry Ivanov (Germany)

The working group explores and generates novel solutions for supply chain design and management. Indeed, Supply chains are emblematic examples of the renewal of production systems in the last decades. Supply Chains Engineering is an emerging field for Automatic Control applications based on analysis and comprehension of essential principles of production and distribution systems. This scientific domain concerns the methodical evaluation and optimization of production systems, logistics networks, and their management policies to increase the effectiveness of multifaceted demand and supply chains. The major industrial problems and various effective approaches of inventory control in Supply chains, use of Radio Frequency IDentification (RFID) and Internet applications or intelligent storage facilities are being examined. Radical changes in the criteria that express the new objectives of production systems and logistics are on-going: Just-In-Time (JIT) requirements, dynamic scheduling, dynamic pricing, etc. In addition, the main concerns of outsourcing are being detailed. In particular, a vendor selection and evaluation models are being developed. Certainly, warehouses are critical components of supply chains. In this WG, their usefulness is highlighted and their various functions and equipment are being analysed. The design stage is also being extensively considered via developing storage algorithms as well as examining warehouse sizing static and dynamic models.

WG 2 "Advanced multi-criteria applications in manufacturing and logistics"; Chairs: Prof. Dr. Lyes Benyoucef (France), Dr. Aguirre Hernan (Japan) and Prof. Dr. Farouk Yalaoui (France)

The new competition is a major upheaval affecting every aspect of how enterprises organize and operate. The evolution from single enterprise with a high vertical range of activities toward enterprise networks offers new business opportunities especially for small and medium enterprises (SMEs) that are usually more flexible than larger companies. However, in order to make a successful commitment to an enterprise network, expected performance and benefits have to be carefully evaluated and balanced for a company to become a partner of the right network and for the right tasks. All these issues have to be taken into account in order to find an efficient, flexible, and sustainable solution.

In the area of manufacturing and logistics, supply chain networks involve transformation processes from raw materials to finished products, through several stages of manufacturing, assembly, distribution, and delivery to customers. They have taken a prominent role to integrate people, information and products across integrated supply chain boundaries including management of various manufacturing, logistics and retailing operations such as in manufacturing, warehousing and distribution of goods and services. Decisions involving customer profiling, new product development, retail marketing, and sales patterns are immensely refined using innovative multi-criteria approaches. Also, as such decisions have an impact on the overall integrated logistic network processes, it is important that innovative multi-criteria-based tools also be linked to integrated supply chain management applications. The working group aims to align latest practice, innovation and case studies with academic frameworks and theories. It will cover 
the latest research results and efforts at different levels including quick-response system, theoretical performance analysis, performance and capability demonstration, hoping to cover the role of multi-criteria approaches in optimizing manufacturing and logistics.

WG 3 "Design and Control of Reconfigurable Manufacturing Systems"; Chairs: Prof. Dr. Olga Battaïa, Prof. Dr. Xavier Delorme (France), Dr. Rita Gamberini (Italy) and Prof. Dr. Manoj Kumar Tiwari (India)

The working group investigates and develops novel modelling approaches for designing and management of reconfigurable machining, assembly and disassembly systems. One of the main characteristics of these automated systems is that they use reconfigurable manufacturing technologies for fast adaptation to changes in the quantity and mix of products. Indeed, the industry's new requirements for manufacturing systems given the shorter and shorter product runs and the need for more customization. The production systems should be designed to be able to make changes in its physical configuration to answer market fluctuations in both volume and type of product. One of the principal characteristics of reconfigurable manufacturing systems (RMS) is modularity: in a reconfigurable manufacturing system, all the major components are modular (system, software, control, machines and process). Selection of basic modules and the way they can be connected provide systems that can be easily integrated, diagnosed, customized, and converted. An RMS is also supposed to quickly integrate new technologies to improve its efficiency. RMS is assumed to be the perfect tool for the new era of mass customization that requires simultaneously the productivity of dedicated system and the flexibility of agile manufacturing system. The aim of this working group is a review on this topic, more particularly on the challenges of flexibility and reconfigurability for assembly, disassembly and machining systems.

WG 4 "Advances in Integrated Maintenance Management"; Chairs: Prof. Dr. Anis Chelbi (Tunisia), Prof. Dr. Ali Gharbi (Canada) and Prof. Dr. Nidhal Rezg (France)

Ameliorating the situation of an industry requires certainly reducing costs and maximizing the customer satisfaction. These two aims cannot be achieved without good management and a good know how while making decisions. These decisions are generally associated, at least, with three levels of the hierarchical planning process: strategic, tactical and operational levels. Generally, manufacturing industries aims at determining the most adequate integrated maintenance production strategies which helps them to optimize the system exploitation and to reduce several costs. Releasing such an efficient planning urges firms to have a global vision on their production and maintenance process which may be looked upon as an inter-dependent set of sub systems performing various functions including ordering raw materials, assembling pieces, controlling quality, repairing machines, storage, etc. One of the key issues in up-to-date research in integrated maintenance production strategies is to develop a set of new intelligent integrated maintenance policies which integrate maintenance and production aspects with taking into account several environment constraints. The real goal is to face the various contemporary industrial constraints in order to optimize the system exploitation and to reduce several costs. The WG aims to present and analyse new methods and tools of new integrated maintenance strategies, in order to increase service level, system availability with reducing several costs. This objective can be realized by new organization of combined maintenance tasks, production planning, and resources of several activities.

WG 5 "Risk, analytics and operations"; Chairs: Prof. Dr. Desheng Dash Wu (Sweden) and Prof. Dr. Charles S. Tapiero (USA) 
Operations Risk Analytics will enable the growth and understanding of best practices in operations, e.g., pricing functions. Banks are processing millions of transactions every day in order to protect against fraud and terrorist financing. Energy companies monitor operations process and customer activities to protect again abnormal and predict spikes in demand. Risk analytics in business intelligence represents data-oriented techniques to supplement business systems for better risk-based decision making. Risk performance analysis in manufacturing intelligence uses advanced data analytics, modelling and simulation to produce a fundamental transformation to new product-based economics through internet--based service enterprises and demand--driven supply chains. Risk evaluation plays key roles in emerging areas such as bio-manufacturing, nanotechnology, and energy. We see a dramatic increase in the use of predictive analytics in these and many other areas. This working group will bring together scientists who have different backgrounds and disciplines, and provide a set of opportunities to discuss these open issues.

WG 6 "Intelligent methods and systems supporting supply chain decision making"; Chairs: Prof. Dr. Michael Freitag (Germany) and Prof. Dr. Enzo Morosini Frazzon (Brazil)

The activities of the working group cover the technology-based integration of different supply chain tasks, such as: production planning, scheduling and control, transportation and logistics planning, scheduling and control, inventory planning and warehouse management and operations, manufacturing systems operations as well as coupled services and technologies which can lead to improved supply chains. It includes such topics such as modelling, simulation, analysis, and control of manufacturing processes; Monitoring, diagnosis and maintenance of manufacturing systems; Smart manufacturing systems and Industry 4.0 technologies. Special attention will be directed towards practical relevance and approaches that can foster innovation in manufacturing supply chains.

WG 7 "Human factors and ergonomics in industrial and logistic system design and management"; Chairs: Prof. Dr. Daria Battini (Italy), Prof. Dr. Fabio Sgarbossa (Italy), Prof. Dr. Christoph Glock (Germany), Dr. Eric Grosse (Germany)

Generally, human factors (perceptual, mental, physical and psychosocial aspects) determine the performance of industrial and logistic systems to a large extent if human operators are employed. This aspect becomes more challenging in light of demographic changes, which will likely put human factor-related issues in logistics - such as the risk of developing musculoskeletal disorders in labour-intensive work environments, for example - on top of the agendas in many companies. In addition, the consequences of using innovative technical solutions to support industrial and logistics processes, such as augmented reality or motion capturing, is not yet fully understood in light of human performance and errors.

This working group aims at investigating the development of innovative approaches for the integration of human factors in industrial and logistic system design. Topics may include, but are not limited to:

- Ergonomics in operations and logistics management

- Learning and forgetting aspects in industrial systems

- The impact of system design on human errors

- Error-free systems

- Reduction of injury risks in manual operations

- The impact of demographic changes on industrial systems 
- The Impact of digital transformation on the future of work

Recent publications of the TC 5.2 working groups are depicting the whole spectrum of research results that progress state-of-the-art and contribute to practical decision-making support (Amodeo et al. 2015, Battini et al. 2017, Dolgui et al. 2018, 2020, Frazzon et al. 2018, Ivanov and Sokolov 2012, Ivanov et al. 2016, 2018, Olson and Wu 2015). Besides, the cross-group collaboration has been recently established and resulted in a number of remarkable publications (Battaïa et al. 2018, Cavalcantea et al. 2019, Fragopane et al. 2020).

Regarding the future plans, Industry 4.0, Resilient Supply Chains, Digital Manufacturing, Analytics applications to manufacturing, human factors, Industry 4.0, Artificial Intelligence belong to major topics of interest within IFAC TC 5.2. For this purpose, new working groups on Industry 4.0, cloud manufacturing, and artificial intelligence will be created in very near future.

\section{Papers included into this special issue}

The articles included into this issue were selected at IFAC MIM 2019 conference and prepared by members of IFAC TC 5.2. They are focused on the most challenging topics at the moment and present either surveys of literature or a position/vision papers.

Human-robot collaborative systems in manufacturing. The state of the art presentation "Operations management issues in design and control of hybrid human-robot collaborative manufacturing systems: a survey" by Seyyed Ehsan Hashemi-Petroodi, Simon Thevenin, Sergey Kovalev, and Alexandre Dolgui (TC 5.2 Working Group WG 3 "Design and Control of Reconfigurable Manufacturing Systems") analyses the literature on operations management issues of new manufacturing systems based on human-robot collaboration. Such systems are a trade-off between fully automated production lines using robots, with high speed, accuracy, tirelessness and force, but also high costs, and manual systems with human workers which are intelligent, creative, flexible and able to work with different tools in different situations. A combination of these resources frames is a human-machine/robot (hybrid) system, in which humans and robots perform a variety of tasks (manual, automated, and hybrid tasks) in a shared workspace. The authors extend the existing surveys in this domain by studying especially two types of interactions and optimization problems, i.e., dual resource constrained (DRC) and human-robot collaboration (HRC) optimization problems. Different characteristics of workforce and machines/robots such as heterogeneity, homogeneity, and ergonomics are analysed. The features and optimization challenges for hybrid systems are proposed. The authors conclude that ergonomics, safety, completion time, flexibility, and reconfigurability are the main focuses in optimization of such systems. Studying flexibility and reconfigurability in hybrid systems is one of the main research avenues for future research.

Supply chain control. Narjes Kandil, Olga Battaïa, and Ramzi Hammami analyse in their survey paper "Globalisation vs. Slowbalisation: A literature review of analytical models for sourcing decisions in Supply Chain Management", a research work from the scopes of TC 5.2. Working Groups WG 1 "Supply Networks Engineering" and WG 5 "Risk, analytics and operations", some generalized decision-making trade-offs in the context of the mainstream of globalization and a new trend of slowbalization. The authors review the existing literature including both empirical and analytical papers on the sourcing and location decisions in Supply Chains. Building upon definitions of different sourcing strategies, e.g., insourcing, outsourcing, offshoring and reshoring, they present the drivers for each strategy and how they can be incorporated in the analytical models. The research perspectives in the field are discussed. 
Socio-cyber-physical perspective of digital manufacturing. The vision paper "Manufacturing networks in the era of digital production and operations: A socio-cyber-physical perspective" by Enzo Morosini Frazzon, Icaro Agostino, Elke Broda E and Michael Freitag contributes to a new vision that aims at addressing distributed decision-making in digital and integrated manufacturing networks under a socio-cyber-physical systems perspective. In this exploratory study stemming from the research in TC 5.2. working group WG 6 "Intelligent methods and systems supporting supply chain decision making", the authors present a narrative review of current research literature, followed by a research framework proposition. They conclude that manufacturing and control research communities need to embrace a convergent vision addressing: (i) how manufacturing networks could be planned and controlled in the future, (ii) which decision-making methods and approaches can be used, as well as (iii) which technology drivers are fostering new research opportunities with practical impact. In this context, the authors indicate potential future research avenues and agenda.

Human factors. The vision paper "Human Factors in production and logistics systems of the future" by Fabio Sgarbossa, Eric Grosse, W. Patrick Neumann, Daria Battini, and Christoph Glock summarizes the progress, challenges and opportunities in this research field, stemming from the activities in the Working Group 7 (WG7) "Human factors and ergonomics in industrial and logistic system design and management" of TC 5.2. The authors discuss the development of this research stream in light of the contributions presented in invited sessions at related IFAC conferences in the last 5 years. The TC5.2 framework is adapted to include a human-centred perspective. Based on this discussion, a research agenda is developed that highlights the potential benefits and future requirements for academia and society in this emerging research field. The authors identify and comprehensively discuss promising directions for future research on human factors in production and logistics systems that include consideration of diversity of human workers and an in-depth integration of Industry 4.0 technologies in operations processes to support the development of smart, sustainable, human-centred systems.

Inventory control in Industry 4.0. The survey paper "Control of Inventory Dynamics: A Survey of Special Cases for Products with Low Demand" by Boris Sokolov, Valery Lukinskiy and Vladislav Lukinskiy stems from the activities of TC 5.2 Working Group WG 1 "Supply Network Engineering" and is devoted to a generalization of special cases of inventory management with low demand. The results of one- and two-dimensional stock classifications are presented. The limitations of the economic order quantity (EOQ) model for inventory management strategies are determined. The authors analyse the methods of inventory calculations in Industry 4.0 for products with low demand. Moreover, integrated time series forecasting models, along with algorithms to estimate the inventory forecasting parameters, are proposed. Analyses for different time series are presented to demonstrate the applications of the methods to estimate the stock consumption characteristics.

\section{Conclusion}

In this position paper, we summarized history, current activities and future topics of IFAC Technical Committee (TC) 5.2 "Manufacturing Modelling, Management and Control". IFAC TC 5.2 was established in 1993 and has been successfully developed over almost three decades. Currently, IFAC TC 5.2 counts 91 members from 22 countries, 7 working groups are active. These developments have been progressed by outstanding services of the TC 5.2 chairpersons A. Villa (1993-1999), S. Y. Nof (1999-2002), L. Monostori (2002-2008), J. Ceroni Diaz (20082011), A. Dolgui (2011-2017), and D. Ivanov (2017- ). 
Number of participants at the major IFAC TC 5.2 event, i.e., IFAC MIM conference, has been continuously increased reaching for the last three events very high numbers (450 at MIM 2013 in St. Petersburg, 540 at MIM 2016 in Troyes, 740 at MIM 2019 in Berlin). With all this, IFAC MIM became one of the worldwide major events on control, industrial engineering, and production management. The 9th IFAC Conference MIM 2019 that was recently organized by IFAC TC 5.2 in Berlin, Germany was attended by 740 participants. It was co-sponsored by IFIP, IFORS, IISE, and INFORMS. The MIM 2019 mission was to connect Control, Industrial Engineering, OR and Computer Science for better management decision-support systems in digital, resilient and sustainable manufacturing and supply chains in the era of Industry 4.0, to present and discuss emerging topics in modern manufacturing modelling, management, and control. MIM 2019 followed a rich tradition of previous IFAC conferences and symposia in Manufacturing and Logistics. More than 850 submissions from 61 countries were received. Finally, after a careful peer-review process with a voluntary involvement of 94 members of International Program Committee from 31 countries and more than 700 reviewers, 540 articles have been selected for presentation at the conference. In the outstanding program of MIM 2019 were included: 7 plenary talks, 5 keynote talks, 540 presentations in 18 parallel tracks with 121 invited, special and regular sessions, 4 industrial sessions, and several thematic special sessions (e.g., Meet the Editor session with Editor-in-Chiefs of the leading international journals). Several exhibitors (e.g., The AnyLogic Company, SupplyOn AG, Springer), industrial tours at BMW, Fraunhofer IPK, Rolls Royce, Siemens, and Stadler, and 3 Industrial Workshops shaped the industrial program of the IFAC MIM 2019.

The main scope of IFAC TC 5.2 are models for manufacturing management and control which range from optimization and knowledge-based models to simulation models (discrete-event and continuous), all of them oriented to design and control of production systems and supply networks. In particular, models of manufacturing tasks in production, models of manufacturing process design and inventory control, models of supply networks aiming at the design, planning and control of coordinated production-logistics systems, and models of Industry 4.0, cyberphysical systems, computer-aided, communication-based and Internet-based procedures and processes with the aim of accomplishing the functions listed in (a) - (c) are of interest for TC 5.2. members and 7 working groups.

To summarize, the activities of the IFAC TC 5.2 Manufacturing Modelling for Management and Control are devoted to promote the development of management decision-support systems in digital, resilient and sustainable manufacturing and supply chain systems in the era of Industry 4.0 based on combination of Control, Industrial Engineering, Production Management, Operations Research and Data Science. We encourage and invite international collaboration in research of mutual interest. The next, $10^{\text {th }}$ IFAC MIM Conference is planned for summer 2022 in Nantes, France.

\section{Acknowledgement}

We cordially thank Prof. Dr. Francoise Lamnabhi-Lagarrigue, Editor-in-Chief of Annual Reviews in Control for her unconditional support and guidance of this Special Issue for the $9^{\text {th }}$ IFAC conference MIM 2019 and IFAC TC 5.2. 


\section{References}

Amodeo, L., Talbi EG, Yalaoui F. (2018). Recent Developments in Metaheuristics. Springer.

Battaïa O., A Otto, F Sgarbossa, E Pesch (2018). Future trends in Management and Operation of Assembly Systems: From customized assembly systems to cyber-physical systems. Omega, 78, 1-4.

Battini, D., M Calzavara, A Otto, F Sgarbossa (2017) Preventing ergonomic risks with integrated planning on assembly line balancing and parts feeding. International Journal of Production Research, 55(24), 7452-7472

Cavalcantea, I.M., Frazzon E.M., Forcellinia, F.A., Ivanov, D. (2019). A supervised machine learning approach to data-driven simulation of resilient supplier selection in digital manufacturing. International Journal of Information Management, 49, 86-97.

Dolgui A., Ivanov D., Potryasaev S., Sokolov B., Ivanova M., Werner F. (2020). Blockchainoriented dynamic modelling of smart contract design and execution control in the supply chain. International Journal of Production Research, DOI:10.1080/00207543.2019.1627439.

Dolgui, A., Ivanov, D., Sokolov, B. (2018). Ripple Effect in the Supply Chain: An Analysis and Recent Literature. International Journal of Production Research, 56(1-2), 414-430.

Dolgui, A., Ivanov, D., Sethi S.P., Sokolov, B. (2019). Scheduling in production, supply chain and Industry 4.0 systems by optimal control. International Journal of Production Research, 57(2), 411-432

Dolgui, A., Proth, J.-M. (2010). Supply chain engineering: Useful Methods and techniques, Springer.

Fragapane G., Ivanov D., Peron M, Sgarbossa F., Strandhagen J.O. (2020). Increasing flexibility and productivity in Industry 4.0 production networks with autonomous mobile robots and smart intralogistics. Annals of Operations Research, https://doi.org/10.1007/s10479-02003526-7

Frazzon E.M., Albrecht A., Pires MC., Israel E., Kück M., Freitag M. (2018). Hybrid approach for the integrated scheduling of production and transport processes along supply chains. International Journal of Production Research, 56(5), 2019-2035

Ivanov, D., Dolgui, A., Sokolov, B. (2019). The impact of digital technology and Industry 4.0 on the ripple effect and supply chain risk analytics. International Journal of Production Research, 57(3), 829-846.

Ivanov, D., Sethi S., Dolgui A., Sokolov, B. (2018). A survey on the control theory applications to operational systems, supply chain management and Industry 4.0. Annual Reviews in Control, 46, 134-147.

Ivanov, D., Sokolov B. (2012). The Inter-Disciplinary Modelling of Supply Chains in the Context of Collaborative Multi-Structural Cyber-Physical Networks, Journal of Manufacturing Technology Management, Vol. 23(8), 976-997.

Ivanov, D., Sokolov, B., Dolgui, A., Werner, F., Ivanova, M. (2016). A dynamic model and an algorithm for short-term supply chain scheduling in the smart factory Industry 4.0. International Journal of Production Research, 54(2), 386-402.

Nof, S.Y. (2007). Collaborative control theory for e-work, e-production, and e-service, Annual Reviews in Control, 31(2), 281-92.

Olson DL, Wu D.D. (2015). Enterprise Risk Management. Springer

Panetto H., Iung B., Ivanov D., Weichhart G., Wang X. (2019). Challenges for the cyber-physical manufacturing enterprises of the future. Annual Reviews in Control, 47, 200-213.

Sethi SP, Yan H, Zhang H, Zhang Q. (2002). Optimal and Hierarchical Controls in Dynamic Stochastic Manufacturing Systems: A Survey. Manuf Serv Oper Mant, 4(2):133-170.

Spiegler, VLM, Naim, M. M., Towill, D. R., Wikner, J. (2016). The value of nonlinear control theory in investigating the underlying dynamics and resilience of a grocery supply chain. International Journal of Production Research, 54(1):265-286 
Wang, X., Disney, S. M., (2012). Stability analysis of constrained inventory systems. European Journal of Operational Research 223, 86-95. 